\section{Partial Development of the Corpus Callosum}

As an individual who expected tractography to provide new information about the development of the corpus callosum in cases of dysgenesis, I read with interest the article by Wahl et al. ${ }^{1}$ The authors' excellent work demonstrates that in humans with corpus callosum dysgenesis, the connectivity of the tracts coursing through the corpus callosum is highly variable and the topology of the tracts does not follow the same organization demonstrated in the normal corpus callosum. They realized that their results cannot be explained by a theory in which the callosal remnants were formed by arrested growth of a normally developing corpus callosum. On the basis of animal experiments and our own morphometric study of the partially developed corpus callosum in patients, we had previously concluded that the partially developed corpus callosum in at least some patients was due to continued development of the commissure and not to arrested growth. ${ }^{2}$

Wahlsten ${ }^{3}$ first proposed that the presence of the deficient corpus callosum in genetically abnormal mice was due to delayed but continued development of the commissure. Wahlsten reached his conclusion by studying different-aged fetuses of mice genetically destined to have callosal dysgenesis. Experiments, which used horseradish peroxidase to label the neurons that passed through the partially developed corpus callosum of mice with callosal dysgenesis, ${ }^{4,5}$ demonstrated results similar to that of the Wahl et al human study. ${ }^{1}$ They showed variability in the connectivity ${ }^{4}$ and topology ${ }^{5}$ of the tracts in the partially developed corpus callosum. This could only occur if the corpus callosum continued to develop and would not occur if its development was arrested.
In our morphometric study of the partially developed corpus callosum in patients, the commissures developed with a wide variety of shapes and locations that could not be fully explained by a theory of arrested growth of a normally developing corpus callosum. In light of the animal studies, we theorized that as in mice, at least some human cases of callosal dysgenesis are not caused by arrested growth of the corpus callosum but by continued development of the corpus callosum that attempts to compensate for early abnormalities in the evolution of midline structures. ${ }^{2}$ The findings of the study by Wahl et $\mathrm{al}^{1}$ support that theory.

\section{References}

1. Wahl M, Strominger Z, Jeremy RJ, et al. Variability of homotopic and heterotopic callosal connectivity in partial agenesis of the corpus callosum: a $3 \mathrm{~T}$ diffusion tensor imaging and Q-ball tractography study. AJNR Am J Neuroradiol 2009;30:282-89 Epub 2008 Nov 11

2. Rubinstein D, Youngman V, Hise JH, et al. Partial development of the corpus callosum. AJNR Am J Neuroradiol 1994;15:869-75

3. Wahlsten D. Defects in the fetal forebrain in mice with hereditary agenesis of the corpus callosum. J Comp Neurol 1987;262:227-41

4. Ozaki HS, Shimada M. The fibers which course within the Probst's longitudinal bundle seen in the brain of a congenitally acallosal mouse: a study with the horseradish peroxidase technique. Brain Res 1988;441:5-14

5. Olavarria J, Serra Oller MM, Yee KT, et al. Topography of interhemispheric connections in neocortex of mice with congenital deficiencies of the callosal commissure. J Comp Neurol 1988;270:575-90

$$
\begin{array}{r}
\text { D. Rubinstein } \\
\text { Department of Radiology } \\
\text { University of Colorado at Denver Health Sciences Center }
\end{array}
$$
Aurora, Colo

DOI 10.3174/ajnr.A1521 